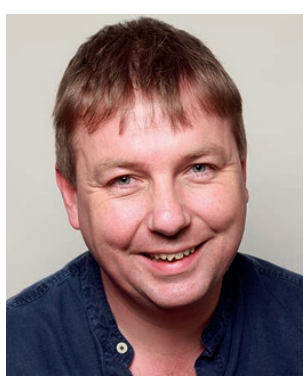

\title{
Policymakers should not act like scientists
}

\author{
Public health officials and politicians often use statistical complexity as an excuse to \\ do nothing, says Danny Dorling.
}

B etween 2010 and 2014 in the US state of Texas, pregnancy-related death rates of women doubled. In August 2016, the New Scientist reported that the most likely reason was the recent closure of clinics for women in the state. However, Carrie Williams, a spokeswoman for the Department of State Health Services told Dallas News that the department considered the issue "a complex problem". Given that an obvious and likely cause could be identified (the rise of deaths occurred in the immediate aftermath of a two-thirds cut in the most relevant health funding), why was this regarded as complex?

As this story attracted more media attention, US public health officials continued to issue banal statements calling for yet another review of the evidence before recommending any action. It would appear that they thought they were doing their job if they merely pointed out that they were aware of the statistics and did not want the trend to worsen or continue. What stopped them saying, "The most plausible reason for the rise in pregnancy-related deaths of women in recent years in Texas is the state health funding cuts in the areas directly related to the health care of these women"?

At the same time as more women were dying in Texas, there was a very large rise in the mortality rates of elderly people in England and Wales. This occurred in the months directly after health and social care services, mostly targeted at the elderly, had their funding dramatically restrained or cut.

In June 2016, data released by the UK's Office for National Statistics revealed that there had been 52,400 more deaths in the year following June 2015 compared with the same period a year before; an annual rise of $9 \%$. These rises in mortality rates are unprecedented in post-war times. In England and Wales, the increase was almost entirely in the population aged over 55 years, predominantly in those aged over 75 , and was largely attributed to dementia and Alzheimer's disease, with influenza being suggested as a minor contributory factor. It was mostly those with long-term care needs who were dying earlier. Two years before this very large rise in elderly deaths occurred, the New Statesman ran a report providing evidence that the initial small cuts in health and social care funding were beginning to result in small rises in elderly mortality. In addition, in late 2016, official data was released for Scotland showing no rise in life expectancy for men and women for the first time in 160 years. Scotland had also experienced health and care funding cuts since 2010 .

\section{Why do you not care?}

So far, not one of the four chief medical offices of the four countries of the United Kingdom has commented in any detail on the rise in deaths, which began in 2012 and 2013, and then became much worse in late 2014 through to mid-2015. Throughout 2016, Public Health England simply stated that it was "monitoring the provisional data" and made occasional mention of influenza, which was not a contributory factor to the majority of additional deaths. Again, why, in this case, is the obvious cause being ignored and focus diverted toward interpretative complexity and the need for ever more data and analysis?

Politicians have to become involved when public health officials fail. Yet, the vague references to uncertainty are also used in the political sphere. In the UK parliament, only one question has been asked so far about the rising death rates. When Ian Blackford, a member of parliament, asked the government to comment on the rising mortality rate, he received the reply "We welcome the overall trend towards longer life expectancy. There are annual fluctuations, but overall the trend remains positive. The key thing is helping people to live longer, healthier lives". His next question should be: "Why do you not care?"

When governments cut health and care funding and many more people die shortly afterwards, the default assumption should be that the two are linked. The onus on authorities should be to find a plausible reason why they are not linked rather than simply describe the issue as complex or confuse the issue by concentrating on minor parts of the story. By adopting the more cautionary language of scientific uncertainty, public health officials and policymakers are deferring action on public health issues, where intervention can save lives.

When politicians and their public health officials act like scientists, they create excuses for inaction. While the role of researchers is to prove the association, for officials and policymakers it is to make immediate decisions when not to do so would most likely prolong or cause harm. As the circumstantial evidence mounts that cutting health and care funding damages health, it is very hard not to conclude that the real reason for delaying action is that the groups who are suffering - mostly poor pregnant women in Texas and elderly, often infirm, people in the United Kingdom - are not a priority for either the politicians or public health policymakers.

\section{Danny Dorling is at the School of Geography} and the Environment, Oxford University Centre for the Environment, University of Oxford, South Parks Road, Oxford OX1 3QY, UK.

e-mail: danny.dorling@ouce.ox.ac.uk 